\title{
Rebalancing power: Participatory research methods in interpreting studies
}

The International Journal for Translation \& Interpreting Research trans-int.org
Svenja Wurm

Heriot-Watt University, $U K$

S.B.Wurm@hw.ac.uk

Jemina Napier

Heriot-Watt University, UK

J.Napier@hw.ac.uk

DOI: 10.12807/ti.109201.2017.a08

\begin{abstract}
A participatory research approach is a qualitative methodology that is inductive and collaborative (Cornwall \& Jewkes, 1995) and relies on trust and relationships (Christopher et al. 2008). This approach is typically used in public health research studies, and has been used specifically to investigate migrant communities and interpreters in public health settings in Ireland (Macfarlane et al, 2009). Participatory research is an approach that enables positive user involvement and empowerment, and enables marginalised 'hidden' voices to be heard. Through purposeful sampling (Patton, 2002), 'information rich' stakeholder groups who have a depth of experience to share can contribute to the research process, thus ensuring that the research is conducted not just on, for and with people (Turner \& Harrington, 2000), but also by people from stakeholder groups.
\end{abstract}

We reflect on two previous research studies to consider an innovative, interactive approach to interpreting research methodology. The studies adopted interactive principles of collaboration between researchers and key stakeholders and thus embedded a participatory approach within the research design. The key principles of participatory research will be outlined, with an overview of the methodologoy for each study and the benefits and challenges of using such an approach in interpreting studies. This paper will highlight how we can use sign language interpreting research to inform methodological approaches to the study of interpreter-mediated interaction generally.

Keywords: interpreting, participatory research, collaborative research, power, sign language

\section{Introduction}

Interpreting studies research frequently includes the involvement of people other than academics, be they interpreters, primary participants or other stakeholders of an interpreted event. Despite exceptions, this is true for research across the board, no matter what the philosophical foundation, the methodological design or the focus of enquiry. Typically, research participants, whether as individuals or as part of a representative group, are regarded as valuable resources, providing perspectives, opinions and insights, 
which exemplify, corroborate, adapt, add to or dispute existing theoretical knowledge.

This paper argues that ethical considerations become paramount in this context, not only in order to mitigate unavoidable researcher bias but also, and perhaps most importantly, to take those who act as informants in research seriously, and thus to produce socially meaningful outcomes. This paper sets out to contribute to putting the reflection of research practices at the forefront. Building on existing work (particularly Turner \& Harrington, 2000), it presents a discussion of participatory research methods, a methodological design already commonly used within other disciplines, which centres on an attempt to redress the status of research participants and which consciously and critically blurs the boundaries between the roles of 'researcher' and 'researched'. After highlighting issues of power in relation to knowledge creation and introducing participatory methods as used within other disciplines, the paper critically reviews two studies that examined sign language interpreting using participatory methods: (i) a study of deaf people's views on access to health care information in Australia (Napier \& Kidd, 2013; Napier, et al, 2014); and (ii) a study of deaf people's perceptions of being known through translation (Napier et al, 2016). This paper thereby aims to address and re-address the power imbalance between 'researcher' and 'researched', critically reshaping the roles associated with these two parties, and discuss the merits of using participatory methods in interpreting studies.

\section{The researcher versus the researched}

The premise for participatory research is the three-fold assumption that (1) research is not created in a vacuum, (2) that knowledge is not absolute and (3) that knowledge is linked to power. The researcher's background, perspective, methods, as well as the contexts in which they work shape the outcome of any research project. Knowledge, as the product of research, is constructed and situated, and only makes sense when regarded as a dynamic concept. In other words, different people develop different kinds of knowledge in different contexts. Which kind of knowledge becomes useful, meaningful and accepted will vary, again, depending on the background and situation. Knowledge created through research provides a different perspective and is thus likely to be different from knowledge developed through practice. The border between these different types of knowledge, however, is somewhat blurred; as practice informs research and research informs practice, they are linked. As an applied discipline, this may be particularly true in interpreting studies, whereby research projects frequently draw on knowledge resources held by other participants, bringing together perspectives from researchers, practitioners and increasingly primary participants and other stakeholders. Perhaps most importantly, a large number of scholars within Interpreting Studies could be categorised as practisearchers (Gile, 1994), i.e. practitioners working as researchers, or researchers working as practitioners. The relationship between practice and research is therefore relatively tight in our discipline. Nevertheless, there is an imbalance as regards the perception of the status of knowledge depending on whom it is associated with and where it is socially located. History unfolded in a way that academia has been regarded as a robust and respected host and creator of knowledge. Universities have traditionally held a "monopoly over knowledge production" (Minkler \& Wallenstein, 2003, p. 7). Representing the "intellectual elite", it is an institu- 
-tion that is embedded in powerful parts of society. Additionally, quality and believability are attached to research that is perceived as "objective, rational, and highly credible" (Gaventa \& Cornwall, 2008, p. 173) and this stands in a hierarchy with other kinds of expertise. At the same time, there seems to be a certain level of suspicion by practitioners of research created within the ivory tower of academia, where the usefulness of research to practice is questioned (see for example the starting point for the debate by Chesterman \& Wagner, 2002). This distance between "researcher" and "researched" has been emphasised within positivist paradigms through a top-down approach to research in an attempt to ensure objectivity. Even academic research that consciously attempts to break free from such approaches through a different methodological design, is, however, still associated with dominant centres of thinking. Who creates knowledge for whom and on what basis become important questions for consideration. This is particularly relevant in contexts where there are additional power hierarchies between those who traditionally do research and those who traditionally are being researched, i.e. research that directly involves marginalised communities. This can be considered the case in our research on sign language interpreting.

As Gaventa and Cornwall (2008, p.172) reinstate, "[p]ower and knowledge are inextricably intertwined". Reviewing different approaches to the relationship between power and knowledge on which participatory methods have been built, the authors outline three traditional understandings of the connection of power and knowledge. Firstly, research has the power to influence public debate and policy. The second dimension of power in relation to knowledge refers to who sets the agenda for knowledge production. The importance is not just the outcome of knowledge, but who gets a say in what is being researched. Gaventa and Cornwall (2008, p. 174) highlight the "[a]symmetries and inequalities of research funding [that mean] that certain issues and certain groups receive more attention than others" as an example alongside a preference of certain, "established" research methods that "allow some voices to enter the process and to discredit the legitimacy of others" (ibid.). The third, and perhaps most significant dimension stresses that "the control of knowledge as a way of influencing consciousness is critical to the exercise of power" (ibid.). The remit goes beyond the direct outcome of research but realises that knowledge has the potential to change popular awareness in order to revoke power imbalances.

While these "three dimensions of power focus on the repressive side of power, and conceptualise power as a resource that individuals gain, hold and wield" (ibid., p. 175), the authors argue for a different understanding of power particularly with reference to Lukes (1974), Foucault (1977, 1979) and Hayward (1998). Power is here regarded in a way that goes beyond a purely negative understanding of the concept as "power of A over B", but instead as a dynamic concept with positive potentiality that has the capacity to evoke social change:

For Foucault, power works through discourses, institutions and practices that are productive of power effects, framing the possibility that govern action. Knowledge is power: 'power and knowledge directly imply one another ... there is no power relation without the correlative constitution of a field of knowledge, nor any knowledge that does not presuppose and constitute at the same time power relations' (1977, p. 27). (Gaventa \& Cornwall, 2008, p. 175, with reference to Foucault 1977, p. 27) 
Participatory methods have at their foundation the aim to rebalance the power dynamics between researcher and researched, maximising the potential for knowledge creation and, more importantly, taking a wider social repositioning seriously.

\section{Towards a (re-)positioning of the researcher in interpreting and translation studies and sign language interpreting and translation studies}

Methodological designs in the disciplines we work in are diverse. Labelled as inter-disciplines (Snell-Hornby, et al, 1994; Wolf, 2007), translation and interpreting studies incorporate a vast variety of methodologies (see for example Hale \& Napier, 2013; Saldanha \& O’Brien, 2013; Angelelli \& Baer, 2015).

Despite an exciting increase in methodological starting points in interpreting studies that foreground reflective research practices and draw on socio-critical paradigms that aim for a repositioning of social structures, such as ethnography or action research, extensive critical discussions of ethical research issues and reflections on methodological design remain markedly scarce, when compared with other disciplines, such as development, educational or health studies. An explicit account positioning the researcher and the role of the (non-academic) participant are often either left implicit or barely tangentially treated. Despite exceptions that begin to explore these issues (e.g. Boéri \& de Manuel Jerez, 2011, and notably Turner \& Harrington, 2000 , which will be discussed further below), methodological considerations typically concentrate on the practical set-up of the research or justification of the methodological paradigm, concentrating on the debate over quantitative versus qualitative methods. Whether reflection and positioning of the researcher are disregarded or just left implied, perhaps in order to make space for discussion of other important elements of research in publications, the absence of such discussion, particularly when compared with other disciplines within the social sciences, implies that there does not currently seem to be a necessity for extensive critical engagement with the subjectivity of the researcher on the one hand, and the careful consideration of the social impact of one's research on the other.

This discussion becomes particularly important when power imbalances are increased when marginalised individuals or communities are involved in research (see e.g. MacFarlane, et al, 2009). With a background in sign language studies in the widest sense, we frequently work with deaf people and are close to discussions that attempt to lay out, understand and find ways of challenging regressive power structures between deaf and hearing people with real impacts on the everyday lives of deaf people. Deaf studies, which is described by O'Brien and Emery $(2014$, p. 28) as a discipline which despite its diversity is inherently political, has laid out quite neatly the historical and current social and institutional oppression of deaf people, which has been paralleled with the oppression of colonised communities as well as other marginalised communities (e.g. Ladd, 2003). Being hearing, thus representing the dominant society, presents us with an inherent privilege that cannot be ignored and should certainly be acknowledged (see Dickinson, 2010; Napier \& Leeson, 2016; Young \& Temple, 2014). This, coupled with the traditional power of the academic researcher, makes it a necessary duty for us to consider our position and be conscious of the power that may be exerted in the research that we are involved with, as well as our incentive for conducting research. As 
O'Brien and Emery (2014, p. 35) remind us:

In Deaf studies, it is not only those who work as academics who have views and thoughts about their language, community, and culture, but also Deaf individuals whose first language is a minority one and whose culture differs from the one that is common to academia. Deaf studies, however, as a minority study, was started and has been dominated by the Other (...).

This is a poignant reminder that research is not conducted in a vacuum and that power imbalances inherent in wider social structures are part of academic structures as well. Conscious awareness and the aim towards a reworking of roles and power structures in knowledge production is a first step to address this imbalance.

In order to rebalance the power in sign language research specifically, the Sign Language Communities' Terms of Reference outlines six principles for conducting research ethically with deaf sign language users (Harris, et al, 2009):

1. The authority for the construction of meanings and knowledge within the sign language community rests with the community's members.

2. Investigators should acknowledge that sign language community members have the right to have those things that they value to be fully considered in all interactions.

3. Investigators should take into account the worldviews of the sign language community in all negotiations or dealings that impact on the community's members.

4. In the application of sign language communities' terms of reference, investigators should recognize the diverse experiences, understandings, and way of life (in sign language societies) that reflect their contemporary cultures.

5. Investigators should ensure that the views and perceptions of the critical reference group (the sign language group) is reflected in any process of validating and evaluating the extent to which sign language communities' terms of reference have been taken into account.

6. Investigators should negotiate within and among sign language groups to establish appropriate processes to consider and determine the criteria for deciding how to meet cultural imperatives, social needs, and priorities.

Working with deaf people was also the starting point for Turner and Harrington (2000) to reflect on ethical research approaches in interpreting and translation studies. Drawing on work within a Feminist paradigm by Cameron et al (1992), the authors argue that "researchers have real responsibilities" when working with research participants and should create relationships that allow for research "on, for and with" people. The first dimension, conducting ethical research on people, fulfils the basic ethical requirements as generally examined by an ethics committee and suggests that the researcher needs to be mindful of the protection of research participants by ensuring that no harm is committed to participants and, that: permission is sought prior to involvement; that anonymity is ensured; disruption to people's lives is kept to a minimum; and by showing consideration to the individual circumstances of research participants and how research may impact on their lives. The second dimension, conducting research for people, highlights the necessity of conducting advocating research by promoting the participant's agenda. Thirdly, and most importantly, the third dimension relates to conducting research with people, i.e. treating "stakeholders essentially as participants or 
co-researchers rather than passive 'subjects' of research", which, according to Turner and Harrington (2000, p. 20), leads to the empowerment of participants by giving voice to the participants themselves. Essentially Turner and Harrington argue for research that includes all three aspects.

Our discussion of participatory methods draws on this basis, and aims to present a model of a comprehensive research design that manages to put some of these premises into practice. By foregrounding the active involvement of non-academic participants, this kind of research lifts the focus from conducting research with people to emphasising research that is conducted by people (cf. Chambers 1994a, p. 953). It thus moves beyond giving voice to those participants who are less heard by having at its core the desire to rebalance the hierarchy between researcher and researched.

\section{Participatory research methods}

Participatory methods have emerged from disciplines in which power relationships between more dominant and less dominant groups are prevalent such as agricultural and development studies often under the notions of Rapid Rural Appraisal (RRA) or Participatory Rural Appraisal (PRA) (e.g. Chambers 1994a; 1994b; 1994c; 1997), as well as in disciplines that are closely related to communities involving people of lesser power, such as educational studies (e.g. Carr \& Kemmis, 1986; McTaggart, 1991; Kember, 2000) and health studies (see, e.g., contributions to Minkler and Wallenstein, 2003). Participatory research frequently happens in contexts that involve what MacFarlane, et al (2009, p. 211) call "'hard to reach' communities".

Research is typically located somewhere between applied social studies and activism (Wallerstein \& Duran 2003, p. 27). While participation frequently happens at all levels in interpreting studies, there are few studies that follow the principles of participatory research as outlined below (though see MacFarlane, et al, 2009). Perhaps more commonly conducted under the label Action Research (see Napier, 2011a), exceptions can be predominantly found in the area of interpreter education (Boéri \& de Manuel Jerez, 2011; Napier, 2005; Pöchhacker, 2010), yet we feel that this approach is yet to be explored to its full potential.

The urge to redesign approaches to research derived from a desire to redress power relationships and ensure that research remains meaningful, relevant and ethical. Rather than presenting distinctive methods of data generation, "the methodological context of their application" (Cornwall \& Jewkes, 1995, p. 1667), the researchers' attitudes and levels of reflection, as well as an awareness of the political impact of one's research is what characterises a participatory research design. As the authors (ibid.) put it: "The practice of participatory research raises personal, political and professional challenges that go beyond the bounds of the production of information." Participatory research is based on a set of key motives, which will be summarised below.

\subsection{From top-down to bottom up: A reversal of power}

While differing approaches to action research may have differing understandings of the location of power, they all share the epistemological critique about the ways in which power is embedded and reinforced in the dominant (i.e. positivist) knowledge production system. (Gaventa \& Cornwall, 2008, p. 178) 
As the name suggests, participants are at the centre of participatory research. The aim is to maximise the potential of bottom-up research. The line between those who are researchers and those who are participants are blurred. In fact, one could go as far as to argue that the label "participants" here describes all people involved in the research process, including those who initiate the research or approach the object of enquiry as researchers, as well as other stakeholders, i.e. those with an active interest in the object other than conducting research. ${ }^{i}$ In other words, all researchers are participants and all participants are researchers. As Cornwall and Jewkes (1995, p.1668) state, "researchers become learners and facilitators, catalysts in a process which takes on its own momentum as people turn together to analyse and discuss".

The aim is to break free from the hierarchy that traditionally exists between the different people involved in the research process. This is the basis for the creation of an atmosphere that enables a co-learning process, and an exchange of knowledge amongst the participants, requiring an openmindedness and a willingness to learn and re-learn.

In practice this looks as follows: rather than involving participants as (passive) informants at a later stage in the research process, leaving the design, contextualisation and interpretation of the findings to the researcher, the idea is to put those who are most closely related to the object of study at the centre of the enquiry and work alongside those with a research background. Rather than participants acting as mere informants who provide data to be analysed by the researcher, knowledge production by researchers and participants is synthesised.

\subsection{Involving participants at all stages of the research}

The importance of involving stakeholders as active participants at all stages, from setting the research agenda and implementation to generation of knowledge and dissemination, is repeatedly stressed. The aim is to enable a dialogue between people with different kinds of backgrounds and funds of knowledge and to explore an object of enquiry together throughout the research process. Stakeholders are involved in setting the agenda, as well as the generation and interpretation of knowledge, and participants are acknowledged in the dissemination of the research. The roles of the participants are fluid and will depend on the context. Presuming a willingness to be flexible, this process "... require[s] researchers to continually adapt their approaches, learn cumulatively from their informants and use the categories and concepts informants provide them with" (Cornwall \& Jewkes, 1995, p. 1668). The central question in determining each participant's role should be how each member can actively contribute to the process without silencing others or hindering an open-minded explorative approach. Instead, delegation

\footnotetext{
${ }^{\mathrm{i}}$ The prevailing literature refers to participants as community members, locals, poor, or less powerful, reflecting the contexts which they describe. In our contexts, such terms do not seem to fit very well. While community members may be involved, we particularly want to stress the involvement of a range of people, including, perhaps, interpreters, primary participants, trainers, members of key organisations, policy makers, or community members affected by interpreting in the widest sense, depending on the aim and nature of the research project. In order to reflect the diversity, we opted for the use of the term stakeholder (including all involved in or affected by interpreting processes).
} 
of contributions should maximise the sharing of resources, funds of knowledge and strengths.

Without explicitly addressing participatory methods, O'Brien and Emery (2014, p. 34) provide some examples of how this could be manifested when deaf and hearing people are involved, arguing that deaf people may be able to offer the linguistic and cultural abilities in order to work closely with other community members, while hearing researchers:

can use the strength of their institutionalized cultural capital (i.e., academic degrees and qualifications) and linguistic capital in the official language of the institution to justify their involvement or claim on the field of deaf studies, advantages which, for reasons discussed earlier, deaf people may not have.

Stoecker (2003) describes a number of roles academics may take in the process, including the initiator, the consultant and the collaborator. Establishing effective collaborative working practices, particularly when aiming to challenge the social status quo, is difficult and will require sensibility and flexibility. As Wallerstein and Duran (2003, p. 35) emphasise, "participation should not be seen as a magic bullet but as a complex and iterative process, which can change, grow, or diminish, based in the unfolding of power relations and the historical and social context of the research project."

\subsection{Moving away from traditional research methods}

One of the inherent aims of participatory methods is to re-evaluate old knowledge providing new perspectives. While the methods themselves do not make research participatory, researchers working in this area have made efforts to redefine the methods used in order to generate knowledge. While the research agenda within traditional methods such as surveys or interviews remains, to varying degrees, set by the researcher, participatory research moves to employ methods of knowledge generation which allow for joint exploration of ideas. "Researchers become learners and facilitators, catalysts in a process which takes on its own momentum as people turn together to analyse and discuss." (Cornwall and Jewkes 1995: 1668). Such an approach thereby aims to break the limitations of more traditional data generation methods to avoid a perpetuation of dominant thinking by a pre-set agenda and knowledge through the structure of the instruments alone.

Instead, participatory research methods aim to enable the creative and playful exploration of ideas employing forms of verbal as well as non-verbal expression, including visual explorations such as diagramming, mapping, modelling, estimating, scoring and ranking with everyday objects (cf. Chambers, 1994, p. 595). Chambers (2002) provides ample ideas for creative and playful activities to enable an exploration of ideas, concepts and problems that move away from traditional methods of data generation. These activities are particularly designed to allow for joint exploration by all participants putting the individuals involved on an equal footing.

\subsection{Leading to social change}

The premise for participatory research is that it leads to social change, either through action, an effort to change practice and/or policy, or the raising of public awareness and consciousness. Instead of focusing on "knowledge for understanding", participatory research aims to create "knowledge for action" (Cornwall \& Jewkes, 1995, p. 1667). Wallerstein and Duran (2003, p. 45) 
emphasise the aim of participatory research leading to social change by arguing that it:

is about knowledge creation and the value of practical and critical reason for understanding power dynamics, for recognizing the interconnections between the personal and social and between life worlds and system worlds, and for identifying the barriers and facilitators of human agency and participation toward the goals of action and social change.

\subsection{Reflection}

Perhaps the most important principle underlying participatory research, however, is the presupposition of reflexivity as part of the researcher. Continuous engagement with and reconsideration of everyone's involvement, their respective statuses in a project and their power credentials shape and reshape the research design. Published research routinely includes a reflection on the power dynamics between those involved in the research process. The implications are discussed not only in terms of the particular outcomes of a research project, but also more generally how it impacts the positioning of the participants in wider social structures. Research thus becomes a vehicle to tackle social change by engaging agents who represent different social positions in discussions with each other. A (re-)positioning and reflections of those involved, particularly those who come into the project with more power, is paramount to make the above principles work (Young \& Temple, 2014). Reflexivity is particularly important when conducting cross-language research (Temple \& Young, 2004).

It is this aspect that we believe is the most important asset of participatory research that can be applied in interpreting studies.

\section{Applying participatory research methods in sign language interpreting studies}

Now that we have provided an overview of the benefits of using a participatory approach in order to re-balance power, here we provide examples of how participatory methods can be used to research interpreting and how stakeholders of interpreting can participate in several ways throughout the life of a research project.

Deaf people's views on interpreting have been canvassed in other studies where they were interviewed or participated in focus groups (see for example, De Wit \& Sluis, 2014; Kurz \& Langer, 2004; Napier \& Rohan, 2007; Turner, et al, 2016); and other stakeholders, including hearing users of sign language interpreting services, and interpreters themselves have also been interviewed about their perceptions of the quality of interpreters and interpreting work (e.g., McKee, 2008; Napier, 2011b, 2012; Schofield \& Mapson, 2014; Hale, et al, submitted; Napier, et al, submitted). What is different about participatory research in interpreting studies, however, is not just involvement of stakeholders as research participants, but also in other aspects of the research design, data collection and determination of project outcomes.

Thus we critically review two studies that examined sign language interpreting involving key stakeholders: (i) 'Deaf people's access to health care information': a study of deaf people's views on their access to preventative and on-going healthcare information in Auslan in Australia (Napier\& Kidd, 2013; Napier, et al, 2014); and (ii) 'Translating the Deaf Self': a study of the perceptions of the lived experience for deaf people in only 
being known and understood through interpreters in the UK (Napier, et al, 2016). Both of these studies have adopted a qualitative, inductive methodology to explore interpreting from the perspective of key stakeholders, but have gone beyond using typical ethnographic or qualitative research methods and just including deaf people and other stakeholders as research participants, and involving them in the research design and on-going iterative development of the research.

\subsection{Deaf people's access to healthcare information}

This project was commissioned by the National Auslan Interpreter Booking Service (NABS) in Australia ${ }^{\text {ii }}$, which was responsible for providing sign language interpreters for private medical appointments throughout the country. The aim of the study was to identify any gaps in access to healthcare information for the Australian Deaf community, and addressed the following research questions:

- What is the state for the Deaf community (in Australia) in terms of access to healthcare information?

- What are Deaf (Australian) sign language users' preferences for accessing healthcare information?

The method involved several elements of participatory research: (i) a stakeholder advisory group; (ii) recruitment and training of a deaf research team; and (iii) semi-structured interviews with deaf people throughout Australia.

\subsubsection{Stakeholder advisory group}

A stakeholder advisory group was established with representatives from key stakeholder groups including NABS, Deaf Australia (the representative body for Australian deaf sign language users), the Australian Sign Language Interpreters' Association, the Deaf Society of New South Wales (a community organization that provided sign language interpreting services in the state of New South Wales), Able Australia (the representative body for Australian deafblind people), a medico-linguist, a health care policy expert, an interpreter who worked regularly with indigenous deaf people in rural and remote areas, a deaf indigenous sign language user, an expert in mental health and deafness, and an interpreter with expertise on working with elderly deaf people.

The role of the group was to consult with and advise the research team on issues relating to the methodology, data collection and consideration of results and recommendations. The group met three times with the project team and also had intermittent email contact between meetings. The goal of the first meeting was to present the proposed methodological framework; to identify how participants could be recruited; and to consider any ethical issues. The second meeting involved providing an overview of the literature surveyed, and an update on the data collection process and preliminary themes emerging from the data. The final meeting focused on the presentation of key findings and recommendations from the study. The goal of each meeting was for group members to give feedback to the research team in a collaborative process, with a view to ensuring that the outcomes of the study were of high quality and met the needs of the Australian Deaf community. Although the initial research

ii The study was conducted while the second author Napier worked at Macquarie University in Sydney, Australia. 
design had been decided, it was felt that it was important for the stakeholder group to shape the actual design to reflect and represent the interests of the stakeholders (although there was not the scope to completely change the design for example from a qualitative to a quantitative approach).

\subsubsection{Research team recruitment and training}

An important element of community-based participatory research is the level of trust between participants and researchers (Christopher, et al, 2008). Therefore at the commencement of the project, deaf research assistants were recruited from five cities to conduct interviews in Auslan (Australian Sign Language) with deaf participants in their own state. By involving deaf people as researchers, this ensured that the research questions were explored from an insider's perspective (Headland, et al, 1990).

All the research assistants attended a training weekend workshop, where the objectives of the project were discussed and the research team worked collaboratively to revise the draft interview questions; to agree on criteria for, and identify, potential participants in their home states; and to agree on a procedure for recruiting participants. The research assistants also participated in interview simulations, which were video-recorded and discussed among the group in terms of efficacy, in order to refine the interview procedure so that it would be consistent among all the interviewers. The importance of confidentiality was discussed during the training workshop, and all the research assistants signed relevant confidentiality agreements.

Part of the weekend workshop also focused on the analysis of data using ELAN software, which is a computer program that allows transcription and detailed annotation to be precisely aligned with video data (Johnston \& Schembri, 2005). The research team agreed on a technique for annotating the video-recorded interviews, which would be used as a basis for data analysis.

\subsubsection{Semi-structured interviews}

A total of 72 in-depth semi-structured interviews were conducted with deaf Auslan users, in 9 metropolitan and regional locations across Australia. All the interviews were conducted by the deaf research assistants in Auslan and were filmed so as to free the interviewers from having to take notes while also interacting with the participant. Before commencement of the interviews, the research assistants used an information and consent form to explain the purpose of the study, what would be expected of participants, and to confirm that all the information would remain confidential, with no names or identifying data to be included in any future publications.

Although an interview procedure was developed for all the research assistants to use, they were free to explore any additional areas of interest within the original objectives of the study. The interview procedure involved the collection of demographic information, then a series of questions to prompt discussion about: how they would describe their own health; their most recent health appointments; how much they felt they understood about particular health issues; where they get their health information; and general preventative health information access.

The majority of interviews were conducted with individuals on a one-toone basis, although focus groups of 5-6 people were also conducted in some states as a way of facilitating the involvement of older participants and Indigenous Deaf community members.

Interviews lasted on average between 30-60 minutes. At the end of each individual interview, and at the conclusion of all the interviews in their state, 
all the research assistants followed a post-interview checklist to ensure that they had all the required information and that the data was saved and backed up.

On completion of their first one or two interviews, the research assistants submitted copies to the research coordinator and were provided with feedback, and updates were sent by email to the rest of the research team on any issues that had arisen for them to take into consideration when conducting their own interviews. This process ensured a consistent approach to interviewing across the research team.

\subsection{Translating the Deaf Self}

This interdisciplinary project was funded through an Arts and Humanities Research Council Translating Cultures Theme Research Innovation Grant ${ }^{\mathrm{iii}}$ and sought to investigate the following questions:

- How is translation constitutive of Deaf cultures in their formation, projection and transformation?

- What is the impact of consistently experiencing existence to others as a translated self on personal identity, achievement and well being?

The project was designed to incorporate key approaches to community participatory data generation: (1) Deaf-hearing partnership; (2) a stakeholder advisory group; (3) community participatory groups; and (4) semi-structured interviews and focus groups, with a range of stakeholders.

\subsubsection{Deaf-hearing partnership}

One crucial aspect of the project was that the research team embedded principles of deaf-led research and partnership throughout the research process. The team was a bilingual deaf-hearing group of researchers that were all fluent in British Sign Language (BSL) and had contacts in the British Deaf community and through professional networks for the key stakeholder organisations. All team meetings were held in BSL, and meetings with the stakeholder advisory group (see 5.2.2 below) were also led in BSL, with interpreters provided for the hearing participants from stakeholder organisations that could not sign or had minimal BSL fluency. Deaf participants were recruited by the deaf researchers, and hearing participants by hearing researchers (with one exception - see 5.2.4 below).

The research team also worked in partnership with two Deaf community organisations, who were instrumental in assisting the team to recruit deaf participants and also organise a final dissemination event.

\subsubsection{Stakeholder advisory group}

At the commencement of the project, a stakeholder advisory group (SAG) was established that consisted of representatives of key third sector organisations involved in policy development, advocacy and service provision with the Deaf community. The SAG acted in a monitoring and advisory capacity to the research team to ensure cultural coherence with the values and priorities of the Deaf community from the ethical perspective of research studies, thus seeking

iii Grant reference: AH/M003426/1. Conducted by the second author (Napier) at Heriot-Watt University with Alys Young and Rosemary Oram from the University of Manchester. 
consent on a community-wide basis as well as on an individual one. It also had role in the governance of the conduct of the project.

The role of the SAG was to: promote and assist the project; give insight into the questions being asked and the nature of the project from the perspective of organisations that represent, or provide services to, the Deaf community; review the research design and data generation plans; advise the project team on matters pertaining to the recruitment of participants; evaluate the quality and relevance of the data generated and the interpretation of the data from analyses; and comment on the dissemination plans and a future research agenda. SAG members included representatives from: the British Deaf Association (Scotland), Deaf Action (Edinburgh), Deaf Connections (Glasgow), the Scottish Association of Sign Language Interpreters, and Action on Hearing Loss.

The SAG met three times throughout the project, and was instrumental in advising the team on data collection and findings, and gave advice about how best to disseminate research findings.

\subsubsection{Community participatory groups}

Two Deaf community participatory groups (CPGs) in two sites were established to scope the subject matter of the research study in order to explore the extent to which it is recognizable as an issue to 'ordinary deaf people using interpreters in everyday situations', and to seek their experiences, thoughts and expansions on the core idea. Many deaf sign language users may not previously have had the opportunity to share their views/thoughts on the topic in a discussion group and in their own language, so we felt they might need to be encouraged and guided by someone who they identified with (i.e., another deaf sign language user) and whose experiences and lifestyles may be similar. Three meetings were held with seven deaf BSL users in two different cities.

In order to examine participants' views about their experiences of interacting with hearing people through BSL interpreters, a topic guide with a list of semi-structured questions was displayed on PowerPoint slides. Participants did not see these questions prior to arrival. The topic guide covered questions concerning: participants' good and bad experiences of using interpreters; their thoughts on how they think they are perceived by others when communicating through interpreters; and whether they ever felt that they were not being recognised as a citizen/person or not being included in the dialogue. For the sake of consistency, the CPG meetings were facilitated in BSL by the same deaf research team members.

As a warm-up activity, the discussion started by asking participants to report which situations they use interpreters, which were noted on a flipchart. During the discussion, visual aids were used to support the group in understanding what we were asking, for example, the flipchart was used for diagrammatic representation when we were discussing the seating arrangements when working with an interpreter. Another activity that was prepared in advance and used to stimulate discussion consisted of the group watching a short video clip of an interpreter-mediated scenario. This enabled the group to respond to the video from a non-personal and potentially less threatening perspective. This could be considered as a form of vignette methodology (Barter \& Reynold, 2004), which is typically written but in this case the scenario was presented in BSL in the form of a simulated interpreting situation. Vignette methodology allows researchers systematically to explore issues that could, potentially, be sensitive to research participants as it allows 
participants to control whether they disclose personal information, and can be an effective way to explore issues related to identity (Crafter, et al, 2015).

All CPG sessions took place in a large meeting room provided by the partner organisations, so the venues were familiar to participants. All the sessions were conducted in BSL by two researchers who are both deaf and fluent BSL users: one is a native BSL user and the other acquired BSL at a later age. Each session lasted between 2.5 to 3 hours with a break part way through. Seating was arranged in a semi-circular format so that participants had a clear view of each other. Because they could all see each other, they were able to participate fully and contribute meaningfully to the discussion in BSL.

To ensure full data capture of BSL, three video cameras were used to record the discussion, meaning that responses from all participants could be recorded from different angles and all aspects of the discussion could be captured.

\subsubsection{Interviews and focus groups}

The original plan was to collect data through three focus groups: (1) hearing parents of deaf children; (2) hearing sign language interpreters and (3) hearing work colleagues of dpeople. Data was still collected from these groups, but slight revisions to the method had to be made to introduce one-to-one interviews face-to-face or by telephone. The reason for this change was twofold: (i) that for the hearing colleagues it was easier to find times to fit their availability if doing individual interviews rather than trying to find a suitable time when several people would be available to meet as a group; and (ii) it was more difficult than we had originally envisaged to get consent from enough parents to participate in the study. Therefore agreeing to conduct telephone interviews meant that we were able to interview three parents. There was no change to the method for the purposes of getting input from sign language interpreters, who participated in focus groups as originally planned. So in the end, two focus groups were held with interpreters $(n=7)$; and semistructured interviews were held with hearing colleagues of deaf people $(n=8)$; hearing parents with deaf children $(n=3)$; and also with deaf professionals who will occasionally choose to speak in some contexts $(n=3)$.

Using network and purposive sampling, an information sheet about the project asking for expressions of interest was sent to personal contacts of the researchers through email and social media including Facebook and Twitter. People who responded positively were contacted and provided with information about the date, time and venue of the interviews and a participant information sheet in relation to informed consent. Recruitment materials were made available in both BSL and written (plain) English.

Interviews lasting between and 30-minutes to 1 hour each, and focus groups lasted approximately 1.5 hours. Participants were given a demographic information sheet to complete, and were also provided with a topic guide in advance so they could consider their responses. The topic guide covered questions concerning: participants' good and bad experiences of interpreting; relationships between deaf, hearing people and interpreters, trust and representation. Interviews were all carried out in spoken English by hearing members of the team; apart from the interviews with deaf professionals, which were conducted in BSL by one of the hearing researchers who has experience of interpreting with deaf professionals. Data was recorded either using video cameras or audio recording devices, depending on the language of the interviews, and was analysed using the N-Vivo 10 sort and retrieve CAQDAS 
programme or the ELAN annotation software, where the research team watched / listened to the recordings and allocated codes and made annotations in English. The data was reviewed by all members of the team, thus reinforcing the deaf-hearing partnership and the emic and etic perspectives that the team brought to the data.

\section{Participatory methods: Benefits and challenges}

It is evident that both projects incorporated principles of participatory research, but the second project improved on the methodology of the first project in several ways:

(i) Further regular meetings were held with the research team as a group in order to review the progress of the study, the collection of data, the approach to analysis and the findings.

(ii) The community participatory groups utilized visual methods and video vignettes in BSL to elicit discussions in BSL.

(iii) Data was collected from all key stakeholders, not just deaf people themselves.

(iv) The research team had more dialogue with the Deaf community on a regular basis about the project, through blog posts (in BSL and English) and community information events conducted in BSL in order to provide updates on the project and engage the community in discussions in BSL about the research process and the findings.

(v) Three short drama videos in BSL were created in collaboration with two deaf-led production companies to represent the results, in order to ensure that findings could be disseminated in BSL back to the community.

One final aspect of improvement is that the research team actively engaged in writing reflexive accounts of their involvement in the project. We needed to reflexively examine our involvement in the project as we became more aware of how our identities impacted on our engagement with the research design, and our understanding of what we were seeing in results. We wanted to share among the team what we felt we had brought to the project from our personal and professional experiences, and how our opinions, thoughts and feelings had changed and were continuing to change over the course of the study. Ultimately, the project results influenced us to reflect on our own personal and professional biographies as a bilingual, deaf-hearing research team. In particular, we reflected on how we related to the concept of the translated deaf self, either personally or from the perspective of being hearing/ interpreters observing the phenomenon and the impact that this had on the way we viewed and interpreted the data, and how we felt about it. Introducing reflexivity thus strengthened the validity of the work and brought transparency to the thought processes that have informed the data analysis one of the benefits also identified in doing action research.

Although there are obvious benefits to conducting participatory research, as it directly involves community members in shaping the nature of research, empowering them and giving them ownership of the research outcomes, it is also challenging. In particular, participatory research is time consuming and expensive. There are also other elements to consider, for example: (a) participatory research can expose conflict between participants and stakeholder groups; (b) it can re-enforce power imbalances in the discourse Translation \& Interpreting Vol 9 No 1 (2017) 
that is used; (c) it can be difficult to recognise individuals' strengths without stereotyping; (d) it can be challenging to recognise power imbalances without perpetuating them; and (e) it raises the question how we can ensure that research is really participatory and not just pay lip-service to participatory methods. Moreover, due to the set-up, research can only be conducted on a small scale; generalization in a quantitative sense is impossible; instead, the focus is inherently qualitative.

One of the key challenges to ensuring true community participation is to include community members in the earliest stages of creating research agendas, that is, before the research questions have been formulated and the funding application has been submitted (Emery, 2016). This has not historically been the case in Deaf studies or interpreting studies research, so the research team at Heriot-Watt University made such an attempt to elicit from Deaf community members their ideas for what needs to be researched, by running a workshop at the Congress of the British Deaf Association (Napier \& Webb, 2016). We asked what we need to know, what kinds of research they would like to see, and how they would like to be involved. However, a clearer structure for discussion and more time was needed to examine key themes that need to be researched, how, when and why research should be conducted, and why community members placed higher value on some areas of research than others. What was clear, nonetheless, was that participants felt that research on interpreting is important, and they are keen to be involved wherever possible.

\section{Conclusion}

In this paper we have provided an overview of the principles of community participatory research and participatory research methods, and how the use of participatory research can be used to rebalance power dynamics when conducting research with minority communities. In particular, with respect to doing research with signing communities, this means involving deaf sign language users at all stages of the research process. In relation to interpreting studies, we propose that participatory research is an effective way to involve all key stakeholders in the research process - the community language users, as well as interpreters themselves and other stakeholders in interpreting provision. We believe that applying participatory research methods in interpreting studies is an innovative way to extend the increasingly popular qualitative enquiry into interpreting.

\section{References}

Angelelli, C., \& Baer, B. (2015). (Eds). Researching translation and interpreting. New York: Routledge.

Barter, C., \& Reynold, E. (2004). The use of vignettes in qualitative research. Social Research Update, 25(9), 1-6.

Boéri, J. \& De Manuel Jerez, J. (2011). From training skilled conference interpreters to educating reflective citizens: A case study of the Marius Action Research Project. The Interpreter and Translator Trainer, 5(1). Special Issue: Ethics and the Curriculum: Critical Perspectives: 41-64.

Cameron, D., Frazer, E., Harvey, P., Rampton, M. B. H. \& Richardson, K. (1992). Introduction. In D. Cameron, E. Frazer, P. Harvey, M. B. H. Rampton \& K. Richardson (Eds), Researching language: Issues of power and method (pp. 128). London \& New York: Routledge.

Translation \& Interpreting Vol 9 No 1 (2017) 
Carr, W. \& Kemmis, S. (1986). Becoming critical: Education, knowledge and action research. Lewes, Falmer Press.

Chambers, R. (1994a). The origins and practice of participatory rural appraisal. World Development, 22(7), 953-69.

Chambers, R. (1994b). Participatory rural appraisal (PRA): Analysis of experience. World Development, 22(9), 1253-68.

Chambers, R. (1994c). Participatory rural appraisal (PRA): Challenges, potential and paradigm, World Development, 22 (10), 1437-54.

Chambers, R. (1997). Whose reality counts? Putting the first last. London: Intermediate Technology Publications.

Chambers, R. (2002). Participatory workshops: A sourcebook of 21 sets of ideas and activities. London and Sterling, VA: Earthscan Publications.

Chesterman, A., Wagner, E. (2002). Can theory help translators? A dialogue between the ivory tower and the wordface. Manchester \& Northampton: St. Jerome Publishing.

Christopher, S., Watts, V., McCormick, A., \& Young, S. (2008). Building and maintaining trust in a community-based participatory research partnership. American Journal of Public Health. 98, 1398-1406.

Cornwall, A., \& Jewkes, R. (1995). What is participatory research? Social Science \& Medicine, 41(12), 1667-76.

Crafter, S., de Abreau, G., Cline, T., \& O'Dell, L. (2015). Using vignette methodology as a tool for exploring cultural identity positions of language brokers. Journal of Constructivist Psychology, 28(1), 83-96.

De Wit, M., \& Sluis, I. (2014). Sign language interpreter quality: the perspective of deaf sign language users in the Netherlands. The Interpreter's Newsletter, 19, 6385 .

Dickinson, J. (2010). Access all areas: identity issues and researcher responsibilities in workplace settings. Text \& Talk, 30(2), 105-24.

Emery, S. (2016, November). The concept of community and university partnership. Paper presented at the Bridging the Gap conference, Brighton.

Foucault, M. (1977). Discipline and punishment. London: Allen Lane.

Foucault, M. (1979). The history of sexuality, Part 1. London: Allen Lane.

Gaventa, J. \& Cornwall, A. (2008). Power and Knowledge. In P. Reason \& H. Bradbury (Eds), The SAGE handbook of action research: Participative enquiry and practice (pp. 172-89). Los Angeles, USA: SAGE.

Gile, D. (1994). Opening up in Interpreting Studies. In M. Snell Hornby, F. Pöchhacker \& K. Kaindl (Eds), Translation Studies: An interdiscipline (pp. 14958). Amsterdam \& Philadelphia: John Benjamins.

Hale, S. \& Napier, J. (2013). Interpreting research: A practical guide to interpreting research methods. London: Bloomsbury.

Hale, S., San Roque, M., Spencer, D. \& Napier, J. (submitted). Deaf citizens as jurors in Australian courts: Participating via professional interpreters. International Journal of Speech, Language \& the Law.

Harris, R., Holmes, H. \& Mertens, D. (2009). Research ethics in signing communities. Sign Language Studies, 9(2), 104-31.

Hayward, C. R. (1998). De-facing Power. Politi, 31 (1): 1-22.

Headland, N. T., Pike, K., \& Harris, M. (Eds.). (1990). Etics and emics: The insider/outsider debate. Newbury Park: Sage.

Johnston, T. \& Schembri, A. (2005). The use of ELAN annotation software in the Auslan Archive/Corpus Project. Paper presented at the Ethnographic research annotation conference. University of Melbourne, Melbourne, Australia.

Kember, D. (2000). Action Learning and Action Research: Improving the quality of teaching and learning. London, Kogan Page.

Kurz, K. B. \& Langer, E. C. (2004). Student perspectives on educational interpreting: Twenty deaf and hard of hearing students offer insights and suggestions. In E. A. Winston (Ed.), Educational interpreting: How it can succeed (pp. 9-47). Washington, DC: Gallaudet University Press.

Ladd, P. (2003). Understanding Deaf culture: In search of Deafhood. Clevedon: Multilingual Matters. 
Lukes, S. (1974). Power: a Radical View. London: Macmillan.

MacFarlane, A., Dzebisova, Z., Karapish, D., Kovacevic, B., Ogbebor, F. \& Okonkwo, E. (2009). Arranging and negotiating the use of informal interpreters in general practice consultations: Experiences of refugees and asylum seekers in the west of Ireland. Social Science and Medicine, 69, 210-214.

McKee, R. L. (2008). 'Quality' in interpreting: A survey of practitioner perspectives. The Sign Language Translator \& Interpreter, 2, 1-14.

McTaggart, R. (1991) Principles for participatory action research. Adult Education Quarterly, 41(3), 168-87.

Minkler, M. \& Wallenstein, N. (2003). Introduction to community based research. In M. Minkler \& N. Wallerstein (Eds), Community-based participatory research for health (pp. 3-26). San Francisco, USA: Jossey Bass.

Napier, J. (2005). Making learning accessible for sign language interpreters: A process of change. Educational Action Research, 13(4), 505-523.

Napier, J. (2011a). If a tree falls in the forest, does it make a noise? The merits of publishing interpreting research. Solicited manuscript for chapter in B. Nicodemus \& L. Swabey (Eds.), Advances in interpreting research: Inquiry in action (pp. 121-152). Philadelphia: John Benjamins.

Napier, J. (2011b). "It's not what they say but the way they say it." A content analysis of interpreter and consumer perceptions of signed language interpreting in Australia. International Journal of the Sociology of Language, 207, 59-87.

Napier, J. (2012). Exploring themes in stakeholder perspectives of video remote interpreting in court. In C. J. Kellett (Ed.), Interpreting across genres: Multiple research perspectives (pp. 219-254). Trieste: EUT Edizioni Universtà di Trieste.

Napier, J., \& Kidd, M. (2013). English literacy as a barrier to healthcare information for deaf people who use Auslan. Australian Family Physician, 42(12), 896-899.

Napier, J., \& Leeson, L. (2016). Sign language in action. London: Palgrave.

Napier, J., \& Rohan, M. (2007). An invitation to dance: Deaf consumers' perceptions of signed language interpreters and interpreting. In M. Metzger \& E. Fleetwood (Eds.), Translation, sociolinguistic, and consumer issues in interpreting (pp. 159-203). Washington, DC: Gallaudet University Press.

Napier, J., \& Webb, S. (2016). Back to the future of sign language research: The importance of relationships with the Deaf community. Workshop at the Congress of the British Deaf Association, Torquay, 20-24 July 2016.

Napier, J., Sabolcec, J., Hodgetts, J., Linder, S., Mundy, G., Turcinov, M., \& Warby, L. (2014). Direct, translated or interpreter-mediated? A qualitative study of access to preventative and on-going healthcare information for Australian Deaf people. In B. Nicodemus \& M. Metzger (Eds.), Investigations in healthcare interpreting (pp.51-89). Washington, DC: Gallaudet University Press.

Napier, J., Spencer, D., Hale, S., San Roque, M., Shearim, G., \& Russell, D. (in press). Can deaf people serve as jurors? A study of sign language interpreter mediated jury deliberations in Australia. Sign Language Studies.

Napier, J., Young, A., Oram, R., Skinner, R. \& O'Connell, N. (2016). Translating the Deaf self. Unpublished research report, AHRC UK, Heriot-Watt University \& University of Manchester.

O'Brien, D. \& Emery, S.D. (2014). The role of the intellectual in minority group studies: Reflections on Deaf Studies in social and political contexts, Qualitative Inquiry, 20(1), 27-36.

Pöchhacker, F. (2010) The role of research in interpreter education. Translation \& Interpreting 2(1), 1-10.

Saldanha, G. \& O'Brien, S. (2013). Research methods for Translation Studies. London and New York: Routledge.

Schofield, M. \& Mapson, R. (2014). Dynamics in interpreted interactions: An insight into the perceptions of healthcare professionals. Journal of Interpretation, 23(1), Article 3. Available at: http://digitalcommons.unf.edu/ joi/vol23/iss1/3

Snell Hornby, S., Pöchhacker, F. \& Kaindl, K. (Eds). (1994). Translation Studies: An interdiscipline. Amsterdam \& Philadelphia: John Benjamins.

Stoecker, R. (2003). Are academics irrelevant? Approaches and roles for scholars in community based research. In M. Minkler, \& N. Wallenstein (Eds), Community-

Translation \& Interpreting Vol 9 No 1 (2017) 
based participatory research for health (pp. 98-112). San Francisco, USA: Jossey Bass.

Temple, B., \& Young, A. (2004). Qualitative research and translation dilemmas. Qualitative Research, 4, 161-178.

Turner, G. H. \& Harrington, F. J. (2000). Issues of power and method in interpreting research. In M. Olohan (Ed.), Intercultural faultlines: Research models in Translation Studies I: Textual and cognitive aspects. (pp. 253-65) Manchester: St. Jerome.

Turner, G. H., Napier, J., Skinner, R., \& Wheatley, M. (2016). Telecommunication relay services as a tool for deaf political participation and citizenship. Information, Communication \& Society, http://dx.doi.org/10.1080/ 1369118X.2016.1234633

Wallerstein, N. \& Duran, B. (2003). The conceptual, historical, and practice roots of community based participatory research and related participatory traditions. In M. Minkler \& N. Wallenstein (Eds). Community-based participatory research for health. (pp. 27-52), San Francisco, USA: Jossey Bass.

Wolf, M. (2007). Introduction: The emergence of a Sociology of Translation. In M. Wolf \& A. Fukari (Eds). Constructing a Sociology of Translation. (pp. 1-36) Amsterdam \& Philadelphia: John Benjamins.

Young, A. \& Temple, B. (2014). Approaches to social research: The case of Deaf Studies. New York: Oxford University Press. 